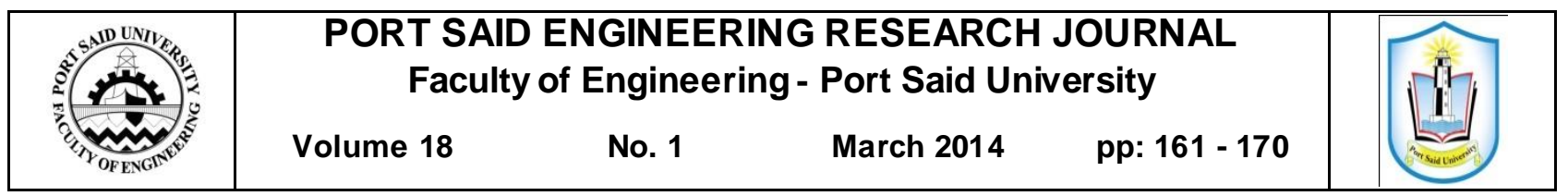

\title{
Challenge of Construction Materials and Solution of Nanotechnology
}

\author{
Mustafa M. Abd El-Hafez ${ }^{1}$, AshrafEl-Mokadem ${ }^{2}$ and Noha M. Abu-Samra ${ }^{3}$
}

\begin{abstract} maintenance and to provide increased living comfort.

\section{STRUCTURE MATERIALS}

Structure materials can be divided into Concrete, Steel, Wood and New Structural Materials.
\end{abstract}

Nanotechnology has a significant impact in the construction materials (structure materials, finishing materials and energy materials). Several applications have been developed for construction sector to improve the durability and enhanced performance of construction components, energy efficiency and safety of the buildings, facilitating the ease of

\subsection{Cement-Concrete}

Concrete is formed by combined cement with sand, gravel and water to be used for construction applications. Concrete is reinforced with metal bars, glass fiber, etc to increase its strength. Concrete is a very versatile material which can be adapted to meet different needs like durability, enhanced ductility, improved thermal and acoustic insulation.

\section{Challenge of Cement - Concrete}

- Reduced $\mathrm{CO} 2$ emissions: Cement industry is one of the most polluting industries in the world in terms of $\mathrm{CO}_{2}$ emissions totaling $5 \%$ of the world's $\mathrm{CO}_{2}$ emissions. Production of 1 ton cement releases 0.8 ton $\mathrm{CO}_{2}$ into the atmosphere from the processing of limestone into clinker. Additionally, the use of fossil fuels during the essentially thermal process adds extra $\mathrm{CO}_{2}$ [1].

- Fast compacting rate: There is an increasing trend towards the use of quick compacting / self-setting concrete for the applications where concrete needs to achieve the required strength in a short time.

- Improved mechanical performance (Durability - Strength): Durability depends on the density of porosity in the concrete structure. Strength of the concrete is related to ultrafine particles. Therefore, having better control of structure would enhance strength and durability of concrete. Also availability of concrete with high performance would make possible construction of structures without need for steel. This would ease the

\footnotetext{
1 Architecture and Urban Planning Department, Faculty of Engineering, Port Said University, Port Said, Egypt, E-mail: whitehouse.egy51@yahoo.com

2 Architecture and Urban Planning Department, Faculty of Engineering, Port Said University, Port Said, Egypt, E-mail: elmokadem@gmail.com

${ }^{3}$ Architecture and Urban Planning Department, Faculty of Engineering, Port Said University, Port Said, Egypt, E-mail: abosamranoha@yahoo.com
}

construction in regions where availability of steel is limited and very expensive [2].

- Enhanced thermal insulation: Thermal insulation of buildings has gained more importance due to the increased concerns related to global warming. In addition to use of additional insulating materials, it is important to increase the insulating performance of concrete [3].

- Ease of maintenance (Service life): Maintenance of concrete structures is very tedious. So it is important that factors that age concrete should be minimized as much as possible [4].

- fire resistant (Fire Protection and Detection): Fire resistance of steel structures is often provided by a coating produced by a spray-on cementitious process. Current Portland cement based coatings are not popular because they need to be thick, tend to be brittle and polymer additions are needed to improve adhesion.

\section{Solution of Nanotechnol ogy}

- Reduced $\mathrm{CO} 2$ emissions: One of the solutions cement manufacturers have brought to this problem is effectively replacing clinker -with other additives (e.g. fly ash, limestone, pozzolan, etc.) - in the production process and reducing the clinker ratio by increasingly introducing new supplementary cementing materials where nanomaterial take part in the scene. The amount of clinker could be reduced /optimized by use of nanoparticles to act as catalyst to driver the reactivity decreasing the Gibbs free energy. Accordingly, this would facilitate also reactions at lower temperatures leading to less fossil fuel consumption [1].

- Fast compacting rate: This could be achieved by having proper ingredients, proper design and thermal treatments. One way to achieve required strength in a shorter time is use of nano-silicates.

- Improved mechanical performance (Durability - Strength): Understanding behavior of cement hydrates would be possible by controlling the behavior in nanoscale through new mathematical tools, modeling tools. Nano-additives increase the durability of concrete 
by increasing the mechanical strength; accordingly, this would have a positive impact on the renovation and repair related expenditures of the existing structures. Super plasticizers are nanopolymers added into concrete to improve its_strength and workability; these can change the surface tension of pore water and change the charge and the density of the cement grain surface [2].

- Enhanced thermal insulation: NanoCon is a NIM (nano insulation materials) with construction properties matching or surpassing those of concrete. NanoCon is basically a homogeneous material with a closed or open small nano pore structure with an overall thermal conductivity of less than $4 \mathrm{~mW} /(\mathrm{mK}$ ) (or another low value to be determined) and exhibits the crucial construction properties that are as good as or better than concrete [3].

- Ease of maintenance (Service life): Defects in the concrete should be detected as early as possible and if possible self-healing mechanisms should be incorporated into concrete that would minimize both the failures and decrease the maintenance costs. Photocatalytic easy-cleaning feature is incorporated into concrete use of nano $\mathrm{TiO} 2$ particles. In the case of its use in concrete apart from bringing self-cleaning feature it also plays a role in cleaning the surfaces, especially motorways, from nitrogen oxide particles which are emitted from exhaust gases [4].

- fire resistant (Fire Protection and Detection): However, research into nano-cement (made of nanosized particles) has the potential to create a new paradigm in this area of application because the resulting material can be used as a tough, durable, high temperature coating. This is achieved by the mixing of carbon nanotubes (CNT's) with the cementious material to fabricate fiber composites that can inherit some of the outstanding properties of the nanotubes such as strength. Polypropylene fibers increasing fire resistance.

\subsection{Steel}

Current research into the refinement of the cementite phase of steel to a Nano-size has produced stronger cables. High strength steel cables, as well as being used in car tires, are used in bridge construction and in precast concrete tensioning and a stronger cable material would reduce the costs and period of construction [1].

\section{Challenge of Steel}

- Improving corrosion resistance, strength formability, and stiffness of steel [1].

- Improvement of strength and decrease of wear of stainles s steel [2].

- Protection against delayed fracturing of joints and bolts in metals structures [5].

\section{Solution of Nanotechnology}

- Although carbon nanotubes (CNT's) are an exciting material with tremendous properties of strength and stiffness, they have found little application as an addition to steel [1].

Nanosized copper particles reduce the surface roughness of steel to impart higher weld-ability and anticorrosion activity [2].

- Manipulating the nano crystallization of the steel matrix.

- Adding vanadium and molybdenum nanoparticles, which reduce the embitterment of grain boundaries in steel by small amounts of hydrogen [5].

\section{Challenge of Solution of Nanotechnology}

- CNT's inherent slipperiness (due to their graphitic nature) makes them difficult to bind to the bulk material and they pull out easily, rendering them ineffective. The high temperatures involved in steel manufacture and the effects of this on CNT's presents a challenge for their effective use as a composite component.

\subsection{Wood}

Wood is the most-used construction material in the United States, while concrete is the most consumed construction material by weight, on a volume basis.

Wood frame construction is relatively inexpensive, easy to build with, and flexible in its structural and stylistic applications. Today, half of the wood products used in housing are engineered wood such as "gluelams" and I-joists. Wood is attractive from an environmental standpoint because it is renewable and can be readily recycled and reused [2].

One of the great problems facing wood construction is rot. Pressure-treating wood can delay the problem, but the metallic salts employed can pose a health and environmental hazard [6].

\section{Challenge of Wood}

- Improve the structural performance and serviceability of wood [1].

- Reduce or eliminate the formation of the random defects that limit the performance of wood [2].

- Improve stiffness and other mechanical properties.

- Produce a less-toxic alternative to traditional treated lumber as a construction material [7].

\section{Solution of Nanotechnology}

- Control over fiber-to-fiber bonding at a microscopic level and nanofibrillar bonding at the nanoscale [1]. 
- Nanocatalysts that induce chemical reactions and make wood even more multifunctional than it is today [2].

- Nanosensors to identify mold, decay, and termites, quantum dot fiber tagging, natural nanoparticle pesticides and repellents, self-cleaning wood surfaces, and

- photocatalytic degradation of pollutants are all envisioned by today's wood engineers [7].

- Using carbon nanofibers and nano clays.

\subsection{New Structural Materials}

Why graphene should be the nanomaterial of choice to strengthen materials used in everything from wind turbines to aircraft wings?

Composites infused with graphene are stronger, stiffer, and less prone to failure than composites infused with carbon nanotubes or other nanoparticles, according to the studies. This means graphene, an atom-thick sheet of carbon atoms arranged like a nanoscale chain-link fence,

could be a key enabler in the development of nextgeneration nanocomposite materials [8].

\section{Challenge of new structural materials}

- Improve strengthen of structural materials.

- Found new structural materials which is serving as both skin and building structure [9].

\section{Solution of Nanotechnol ogy}

- Nanotubes, nanofibers and nanosheets of carbon and similar materials may eventually form the structural skeletons of new buildings [2].

- Transparent carbon nanotube sheets that are stronger than the same weight steel sheets. These can be made so thin that a square kilometer nanotube sheet would weigh only 30 kilograms. The prospect of transparent sheet materials stronger than steel not only holds tremendous energy-saving potential, it promises to dramatically transform conventional assumptions about the relationship between building structure and skin. Could, for example, a super-thin nanotube sheet serve as both skin and structure, eliminating the need for conventional structural systems altogether [9].

\section{FINISHING MATERIALS}

Finishing materials can be divided into Glass, Ceramic tiles, Paint and Coatings.

\subsection{Glass}

In buildings, windows provide sound and heat insulation when they are closed, in addition to their prime task of providing passage of light. Windows are usually made out of float glass or different polymer derivatives. In buildings mostly glass windows are used. According to the requirements and preferences of people and geographical conditions, glass windows are glazed with different coatings. Glazing windows is important for both aesthetic and energy saving purposes [3].

\section{Challenge of Glass}

- Energy efficiency: via heat reflection, heat radiation, transparency / transmittance of sunlight. Windows are preferred to decrease the transmittance of solar heat in warm climates, or to allow passage of solar heat in cold climate zones [1].

- Ease of maintenance: In addition to its traditional use in buildings, today glass is preferred more and more for façade coatings especially at nonresidential coatings. Therefore, easy to clean glass surfaces with scratchproof feature is more and more asked for [2].

- Clear visibility: When coated to reduce its solar heat gain coefficient glass should not lose its visibility via becoming opaque or changing its color.

- Sound insulation: In buildings glass should help to keep outdoor noise as much as possible out of the interior spaces. The higher the STC (sound transmission class) the better the sound insulation performance is [3].

- Fire protection: Glass needs to be fire resistant to ensure the safety.

\section{Solution of Nanotechnol ogy}

- Electrochromic windows, publicly known as smart windows, will soon be on the market as a result of advances in nanotechnology. These windows are designed to respond and adapt to their environment. Electrochromic windows have a glass coated with a thin film of semiconducting nanocrystalline metal oxides which are activated by applying voltage [1].

The particles' colors change from dark to clear colors and vice versa under the effect of an electric charge. Accordingly, windows look transparent or opaque controlling the transmittance of UV light.

- In the glass sector nanotechnology brings again its features through final coatings applied to the glass surface. Nano $\mathrm{TiO} 2$ particle incorporating coatings are applied to have self-cleaning, anti-houling effect [2].

- Thin nanocoatings of vanadium dioxide mixed with just $1.9 \%$ tungsten metal can be applied to windows and act as heat-reflectors, whilst still letting all visible light through.

- For glasses which could control heat and light transmittance nanoparticles of different materials are added to the raw materials of glass at the melting ingot. Nanotechnology would enable windows with air 
purifying, heat radiation and UV rays' transmittance control and also better sound and thermal insulation properties [3].

- Another feature that nanotechnology brings to glasses is fire resistance via addition of fumed silica nanoparticles. When heated, a transparent thin layer formed of fumed silica nanoparticles turn into an opaque fire shield.

\subsection{Ceramic tiles}

Ceramic products used in the construction industry are floor / roof / wall and countertop tiles, sanitary ware and bricks. Ceramic products are manufactured from clays, non-metallic inorganic materials and metallic oxides. Ceramic tiles are thin slabs, generally used as coverings for floors, walls and kitchen and bathroom countertops. Tiles typically are shaped through extrusion or dust pressing at ambient temperature, then dried and fired to maintain their form permanently. The typical production levels for ceramic manufacturing facilities vary from 10 to 50 tons/day for fine ceramics and 450 to 500 tons/day for ceramic tiles [3].

\section{Challenge of Ceramic tiles}

- Ease of maintenance: Initial installation and replacement of broken tiles is a tedious, laborious and expensive process. Easy cleaning is another important feature for energy saving in addition to its comfort [1].

- Hygiene: Construction ceramics, especially sanitary ware products and ceramic tiles, are used in places like hospitals, sanitary-medical rooms, kitchens and public swimming pools/bathrooms, where sterilization is crucial.

- Resistance to harsh environments: Due to the changes in construction trends and environments, nowadays construction ceramics may need to face harsh environmental conditions. Durability, scratch resistance, fire retardancy are therefore important [2].

- Safety: If construction ceramics, especially ceramic tiles that are used at wet areas like swimming pools, showers, and bathrooms, are slippery people may slide and as a consequence get injured. Surfaces of construction ceramics should have anti-skid feature to prevent such incidents [3].

\section{Solution of Nanotechnol ogy}

- New coatings, which enhance the so-called easy-cleaning (or self-cleaning) feature, are mainly formed of nanoparticles, e.g. titanium dioxide (TiO2), silver (Ag). When $\mathrm{TiO} 2$ coatings are applied to enhance the easy-cleaning feature on a surface, the photocatalytic process takes place on the surface. Organic dirt, like bacteria, algae, mould and other germs, on the surface is broken down as a result of the so-called photocatalytic effect minimizing bad odours and ensuring a pleasant clean atmosphere and surface [1].

- Using a coating, which incorporates nanoparticles of $\mathrm{A} 12 \mathrm{O} 3$ as a final layer on construction ceramics, it is possible to obtain highly scratch resistant surfaces.

- Nanoparticles of silver and zirconium are used in coatings especially on sanitary ware products to have anti-bacterial feature on these products. In this case nanoparticles of silver and zirconium are added to glaze composition and fired on the construction ceramic [2].

- Apart from coatings, there are ceramic tiles with micro-pores which absorb water molecules present in the environment and form a nano-sized film of water on the surface. When dirt is present on this surface, it is easily washed away. These special tiles are also claimed to help control humidity in the environment [3].

\subsection{Paint}

Paint is composed of pigments, adhesives, binder, solvent and other additives [3]. Paint is a pigmented chemical liquid which is applied to a substrate, in case of construction to interior and exterior walls / roofs and pipes, simply to protect the surface and also to give a color to the surface it is applied. In today's constructions, paint is also used for energy preservation by modifying light reflection or heat radiation of a surface. Paint is also used on metal surfaces to impede corrosion.

\section{Challenge of paint}

- Anti-settling during storage: Paint should not become viscous and the particles dispersed in the paint should not settle in storage [1].

- Flame retardancy: When exposed to fire paint surface should prevent spread of flame over the surface and also it should suppress the smoke.

- Ease of maintenance: Paints should be easy to clean and stains of harsh chemicals should be removed easily. Also paints should be hygienic, anti-bacterial, anti-odour and anti-microbial [2].

- Short drying time: Paints should dry (cure) as fast as possible without releasing any chemicals to the environment.

- Scratch resistant: Scratches (cracks) are unwanted on the paint surface. Therefore any mechanical impact, thermal change and humidity change in the environment should not lead to cracks [3].

- Barrier properties: When exposed to rain and during its use at humid environments paint should not absorb water vapour which would lead to creep and degradation in insulating properties.

- Resistance to thermal changes: Since interior and exterior spaces encounter temperature changes i.e. 
day to night and seasonal temperature changes, it is important that components of paint should be stable to prevent crack formation [1].

- Long service life with enhanced performances: As it is the case in all products paint should be durable while preserving its performance.

- UV resistance: As mentioned before paints are used on internal walls and external walls for decorative purposes in addition to the other functionalities. Since it is exposed to sunlight after a while the color of the paint starts to fade. So as to keep its color as it is applied on the first day paint should be resistant to UV [2].

- Increased reflectivity: Applications of paint on roof surfaces it is important that paint reflects the UV light and prevents over heating of the buildings.

- Long service life with enhanced performances: As it is the case in all products paint should be durable while preserving its performance [3].

\section{Solution of Nanotechnol ogy}

- Various additives could be added to paint to have significant impacts on the paint. Additives can modify surface tension, improve flow properties and the finished appearance, increase wet edge, etc. Nanomaterials are used as additives like fillers, pigments and etc [1].

- Nanoparticles $\mathrm{TiO} 2, \mathrm{ZnO}, \mathrm{Al} 2 \mathrm{O} 3$, fumed silica and $\mathrm{ZrO} 2$ are added to the paint composition to change the final properties of the paint [2].

- Rheology, settling, surface energy, corrosion resistance and mechanical properties of paint can be improved via addition of nanoparticles into paint. By addition of this nanoparticles paint gets scratch-proof, easy cleaning, air purifying, UV resistant, water repellance, flame retardancy and anti-bacterial feature. Also nanoenhanced paints dry faster than their normal counterparts without releasing any volatile organic compounds (VOCs) that impose health risks [3].

- There are also nanoenhanced paints that improve the buildings (roofs, walls and floors) thermal insulation.

\subsection{Coatings}

Coatings are used as a layer bound to the base material and achieve a wide variety of other performance characteristics - These functionalities are typically applied on coatings for walls (interior or exterior), wooden facades, glass and different road pavement materials -which is come together in the development of new coating systems for almost every surface thinkable from plastics to steel. Within the product group of nanocoatings.

\section{Challenge of Coatings}

achieving a wide variety of performance characteristics:

- Self-clean ing.

- Depolluting.

- Sc ratch-resistant.

- Anti-icing and anti-fogging.

- Antimicrobial.

- UV protection.

- Corrosion-resistant.

- Waterproofing.

\section{Solution of Nanotechnology}

- Many nanoparticles, surfaces treated with them often exhibit more than one of these characteristics:

- Photo-catalytic "self-cleaning" coatings ( $\mathrm{TiO} 2$ or $\mathrm{ZnO}$ ). - Scratch resistant coatings ( $\mathrm{SiO} 2$ or A 12O3).

- Anti-bacterial coatings (adding $\mathrm{TiO} 2, \mathrm{ZnO}$ or Ag).

- UV and IR reflecting or absorbing coatings ( $\mathrm{TiO} 2$ or $\mathrm{ZnO})$.

- Fire retardant coatings ( $\mathrm{SiO} 2)$.

- Self-cleaning surfaces have become a reality thanks to photocatalytic coatings containing titanium dioxide (TiO2) nanoparticles. These nanoparticles initiate photocatalysis, a process by which dirt is broken down by exposure to the sun's ultraviolet rays and washed away by rain. Volatile organic compounds are oxidized into carbon dioxide and water. Today's selfcleaning surfaces are made by applying a thin nanocoating film, painting a nanocoating on, or integrating nanoparticles into the surface layer of a substrate material [2].

- Self-cleaning surfaces enabled by nanotechnology offer energy savings by reducing the energy consumed in cleaning building facades. They also reduce the runoff of environmentally hazardous cleansers. As surfaces self-clean, they are "depolluting", removing organic and inorganic air pollutants like nitrogen oxide from the air and breaking them down into relatively benign elements [10].

- Buildings are subjected to a great deal of wear and tear. Surface scratches can reduce the lifespan of many materials and add to the cost and energy required for maintenance and replacement. The susceptibility of many metals, wood, plastics, polymers and glazing to scratching can limit their potential applications in many areas.

- Many of the multifunctional coatings already mentioned incorporate antimicrobial properties. Antimicrobial nanocoatings reportedly offer the benefits of conventional antimicrobial products.

- Titanium dioxide becomes hydrophilic (attractive to water) when exposed to UV light, making it useful for anti-fogging coatings on windows and mirrors. Polymer coatings made of silica nanoparticles can also 
create surfaces that never fog, without the need for UV light.

\section{ENERGY MATERIALS}

Energy materials can be divided into insulation materials, Lighting and Solar Energy.

\subsection{Insulation Materials (Passive Energy)}

Preventable heat losses in buildings is a major reason for heating / cooling related energy consumption and consequently increased living costs. Insulation reduces unwanted heat losses or heat gains and hence can decrease the energy demands of heating and cooling systems. In addition to thermal insulation, acoustic insulation, fire insulation and impact insulation are also important.

Most common insulation materials are fiberglass, mineral wool and foams of polymer derivatives. Mineral wool and glass are usually used in the form of blankets while polymer derivatives are in the form of rigid sheets. Vacuum insulated panels (VIPs) are also a novel and more innovative insulation system [3].

\section{Challenge of insulation materials}

- Performance: Insulating materials / systems need to have very low conductivity values (high $\mathrm{R}$-value) to act as good insulators [1].

- Impact resistant: VIPs should be resistant to mechanical impacts so that their casing is not damaged during installation and in use [2].

- Hydrophobic: Water vapour or water degrades the insulation performance. For this reason, insulating materials should be hydrophobic and vacuum insulation panels should not retain water in the structure so that it does not retain moisture, because it would effect its insulating performance badly [3].

- Long service life: Insulating materials and VIPs should retain their properties as long as possible.

- Easy and economically feasible installation: is an important requirement for insulation materials' and systems' use in buildings.

\section{Solution of Nanotechnology}

- Nanotechnology can facilitate developing high performance insulation materials / systems. Different forms of insulation solutions, like coatings, vacuum insulation glazing, and nanofoams can be realized [1].

- Silica aerogels are the lightest weight solid material known (less than $0.05 \mathrm{~g} / \mathrm{cm}^{3}$ ) with excellent thermal insulating properties, high temperature stability, very low dielectric constant and high surface area. Since aerogels have very low sound velocity through structures they be as sound insulators [2].
- Foams are very typical insulation materials used in buildings. Thermal resistivity of open porous insulating materials like foams increases when its effective pore size decreases. This well established principle creates the opportunity for nanoporous materials to be used as the core material for extremely effective vacuum insulating panels [3].

In nanoporous materials, thermal conduction through the solid portion has weak temperature dependence and is in some cases hindered by the small size of the connections between the particles making up the conduction path. Thermal conduction by liquids or gases inside the solid is possible, although conduction sizes are only the sizes of the mean-free path for molecular collisions.

- Actual insulation obtained through traditional insulating materials is usually $50 \%$ of the theoretical value. Since nanofoams' pore sizes are about $100 \mathrm{~nm}$, they provide improved insulation by limiting the diffusion of gas molecules [1].

- Aerogel is a form of nanofoam, an engineered material designed for high strength to weight ratio. Aerogel is also known as liquid smoke which is an open cell polymer with pores smaller than 50 nanometers in diameter. Aerogels have the highest internal surface area per gram of material of any known materials because of its complicated, cross-linked internal structure. They also exhibit the best electrical, thermal and solid insulation properties of any known solid [2].

- Vacuum insulation panel (VIP) is an advanced insulation system which provides an insulative value of three to seven times higher than other insulation materials with the same thickness. Vacuum insulation panel encloses a core insulating material enveloped in an airtight casing to which vacuum is applied. Typical core materials are polystyrene, polyurethane and silica. Today it is possible to replace these core materials with nanoporous materials. Combined use of nanoporous materials with VIPs provides very good insulation with an increased $\mathrm{R}$ value. Micro and nanoporous aerogels are very good candidates for being core materials in vacuum insulation panels but they are quite sensitive to moisture. Airtight wrapping is good to prevent moisture intake [3].

- Other means of providing insulation in buildings is through thin films deposited on glass surfaces, windows by increasing the R-value by suppressing radiative heat flow. To do so, coating materials which have low emissivity are used on windows. These so-called low-E materials lower the total heat flow through windows. These coatings are transparent to visible light and opaque to infrared radiation.

\subsection{Lighting (Passive Energy)}

Light emitting diodes (LEDs) is one of the most promising technologies for energy conservation in 
lighting. Organic Light-emitting diodes (OLEDs), is a light-emitting diode (LED) whose emissive electroluminescent layer is composed of a film of organic compounds. This layer of organic semiconductor material is formed between two electrodes, where at least one of the electrodes is transparent. OLED efficiency depends on both, the materials and the device structure to increasing light emission and OLED lifetime.

So me LEDs are projected to have a service life of about 100,000 hours and offer the lowest long term cost of operation available. Potential energy savings from LEDs are estimated at 82 to 93 percent over conventional incandescent and fluorescent lighting. LEDs could save 3.5 quadrillion BTUs of electricity and reduce global carbon emissions by 300 million tons per year, potentially cutting global lighting energy demand in half by 2025 . The principal obstacle to greater adoption of LEDs, however, is cost; they currently cost at least 10 times more than fluorescent ceiling lights [12].

\section{Challenge of lighting}

- Lighting and appliances consume approximately one third of the energy used in building operation. Not only do lighting fixtures consume electricity, but most produce heat that can add to building cooling costs.

\section{Solution of Nanotechnology}

- NanoLEDs (Nanomaterials already have wide use in relation to light, and future uses are seemingly imagined every day in a broad spectrum of application areas). Chromogenic materials are also expected to have improved performances through the use of nanomaterials. Chromogenic materials change their optical properties when subjected to a change in their surrounding energy stimuli. Various kinds of Nanophosphors are already commonly used in many lighting devices.

- Nanowires of indium phosphide (InP) are well suited for miniature light-emitting diodes (LEDs) in the yellow and green color range. The LED is obtained by introducing a junction between differently doped regions within a wire. NanoLEDs are promising for lightemitting displays, integrated optics for communications purposes.

- Quantum dot LEDs are nanoscale semiconductor particles (e.g., silicon or germanium) can be tuned to brightly fluoresce at virtually any wavelength in the visible and infrared portions of the spectrum. They can be used to convert the wavelength, and therefore the color of light emitted by LEDs.

- Organic light emitting diodes (OLEDs) are thin films that are printed onto substrates. When activated by electricity, they provide brighter, crisper displays on electronic devices and use far less energy than LEDs. OLEDs can be applied to any surface, flat or curved, to turn it into a light source. Walls, floors, ceilings, curtains, and tables could all become sources of light. OLEDS have been found to be an extremely efficient lighting source, achieving $100 \%$ efficiency out of a single broad-spectrum light source as opposed to the extremely low efficiency lighting solutions we have today. OLEDs have anther applications. For example TVs will be less than $1 / 4$-inch thick and will be able to be rolled up when not in use.

\subsection{Solar Energy (Active Energy)}

The sun offers a free, renewable source of energy capable of meeting all our energy needs ... if an efficient, economical means of converting solar to electrical energy can be found.

Current silicon-based solar cell technologies, however, have only achieved modest conversion efficiencies at relatively high costs. But conversion technologies are improving, and the market for solar energy is expected to grow from $\$ 15.6$ billion in 2006 to $\$ 69.3$ billion by 2016 . And while solar represents less than 0.5 percent of today's total energy market, it is growing rapidly at 30 percent annually [2].

\section{Challenge of solar energy}

- cost of silicon: Some experts believe that the pace of solar development will be slowed due to the rising cost of its primary raw material, silicon.

Due to increased demand, the price of silicon has skyrocketed from about $\$ 25$ per kilogram in 2004 to roughly $\$ 200$ per kilogram in 2006 . The result has been a significant shortage of solar-quality silicon. The high price and short supply of silicon is expected to pose a serious obstacle to solar power growth, leading some analysts to suggest that solar growth may decline to 20 percent in coming years [14].

Today, at least 90 percent of photovoltaic sales are made from silicon-based solar cells, and at least half of their cost is in the initial silicon wafer.

- Flexibility of thin films: The other dramatic advantage of organic thin films is their flexibility, which will enable their integration into far more building applications than conventional flat glass panels. This will open new architectural possibilities and overcome the aesthetic concerns some architects hold against rigid flat panels, which can hardly be integrated into building facades. Thanks to their flexibility and thinness, thin films could be integrated into windows, roofs, and facades, potentially making almost the entire building envelope a solar collector [15].

- Improved energy storage: Improved energy storage can reduce our dependence on fossil fuels, lowering carbon dioxide emissions from energy production. Currently, energy for homes and offices is not stored onsite. Improved energy storage can reduce 
our dependence on fossil fuels, lowering carbon dioxide emissions from energy production nanotechnology for energy savings will play a much greater role in future markets than nanotech for energy storage [16].

\section{Solution of Nanotechnol ogy}

- Nanotechnology has developed a silicon nanocrystalline ink that could make flexible solar panels as much as ten times cheaper than current solutions. Their silicon process lends itself to low cost, high throughput manufacturing [14].

- While nanotechnology is leading to advances in silicon-based photovoltaics, it appears likely to supplant silicon wafer technology as the primary technology behind solar cells with new nanocrystalline materials, thin-film materials, and conducting polymeric films. Revolutionary thin-film and organic solar cells are now entering the market and are expected to be significantly less expensive than current silicon-based solar cells by 2010 [15].

- Revolutionary thin-film and organic solar cells are now entering the market and are expected to be significantly less expensive than current silicon-based solar cells by 2010. Quantum dot technology could also play a role in solar's future. These dots would be far less costly to incorporate into solar cells than the large crystalline sheets of silicon used today. A photovoltaic device based on quantum dots could have an efficiency of 42 percent, far better than silicon's typical efficiency of 12 percent [16].

- Nanotechnology's possible contributions to the future of energy storage include improved efficiency for conventional rechargeable batteries, new supercapacitors, advances in thermovoltaics for turning waste heat into electricity, improved materials for storing hydrogen, and more efficient hydrocarbon based fuel cells.

- In silicon solar cells today, $40 \%$ of the cost is materials, and the best studies I've seen say that in 5 years that will be reduced to $30 \%$. When you're looking at thin-film solar using nanotechnology, the cost of goods might be $1 \%$ or $1.5 \%$ [17].

- Nanotechnology is leading to advances in silicon-based photovoltaics, and new nanocrystalline materials, thin-film materials, and conducting polymeric films.

- It is estimated that thin film producer Nanosolar's cells are $6.7 \%$ efficient. At that level, just a $3.3 \%$ increase in efficiency to $10 \%$ would allow each cell to capture $50 \%$ more energy, reducing the price per watt by $33 \%$.

\section{DISCUSSION}

We can summarize Nanotechnology which is used in Construction Materials as

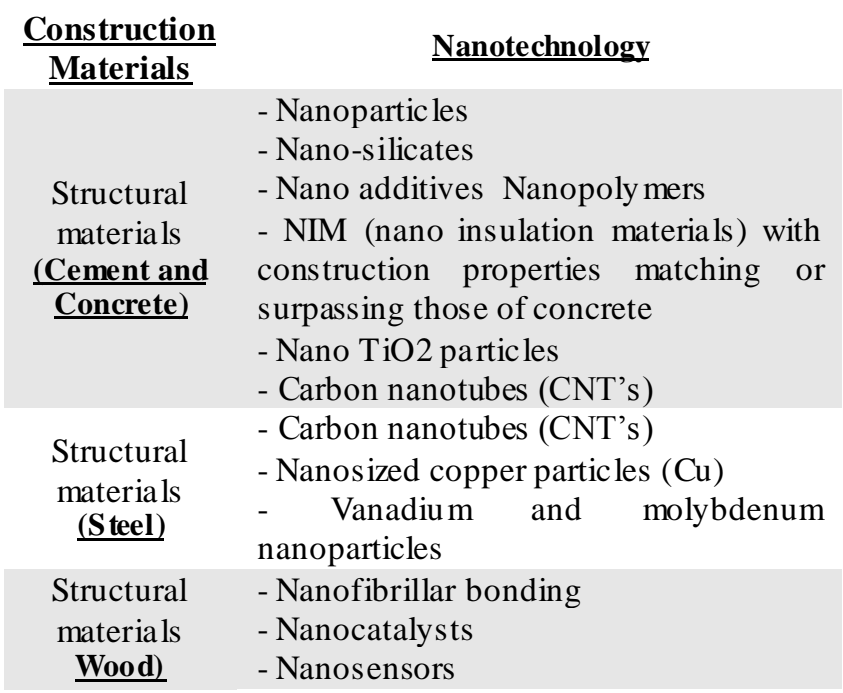

\section{- Carbon nanofibers}

$$
\begin{array}{ll}
\begin{array}{l}
\text { Structural } \\
\text { materials }
\end{array} & \text { - Nanotubes, nanofibers and nanosheets } \\
\underline{\mathbf{N e w}} & \text { - Transparent carbon nanotube sheets }
\end{array}
$$

\begin{tabular}{|c|c|}
\hline $\begin{array}{l}\text { Fin ishing } \\
\text { materials } \\
\text { (Glass) }\end{array}$ & $\begin{array}{l}\text { - nanocrystalline metal oxides } \\
\text { - Nano TiO2 particle } \\
\text { - Nanocoatings of vanadium dioxide } \\
\text { mixed with just } 1.9 \% \text { tungsten metal } \\
\text { - Nanoparticles of different materials } \\
\text { - Fumed silica nanoparticles }\end{array}$ \\
\hline $\begin{array}{c}\begin{array}{c}\text { Fin ishing } \\
\text { materials } \\
\text { (Plastics and }\end{array} \\
\underline{\text { Polymers) }}\end{array}$ & - Carbon nanotubes \\
\hline $\begin{array}{l}\text { Fin ishing } \\
\text { materials } \\
\text { (Drywall) }\end{array}$ & $\begin{array}{l}\text { - Nano-gypsum } \\
\text { - Nanoscale silicon dioxide ( } \mathrm{SiO} 2)\end{array}$ \\
\hline $\begin{array}{l}\text { Fin ishing } \\
\text { materials } \\
\text { (Adhesives) }\end{array}$ & - Self-as sembling nanoscale chains \\
\hline $\begin{array}{l}\text { Fin ishing } \\
\text { materials } \\
\frac{\text { (Ceramic }}{\underline{\text { tiles) }}}\end{array}$ & $\begin{array}{l}\text { - Nanoparticles of titanium dioxide ( } \mathrm{TiO} 2) \\
\text { - Nanopartic les of silver (Ag) } \\
\text { - Nanopartic les of A12O3 } \\
\text { - Nanopartic les of zirconiu m }\end{array}$ \\
\hline $\begin{array}{c}\text { Fin ishing } \\
\text { materials } \\
\underline{\text { (Paint) }}\end{array}$ & $\begin{array}{l}\text { - Nanoparticles of titanium dioxide } \\
\text { (TiO2) } \\
\text { - Nanoparticles of } \mathrm{A} 12 \mathrm{O} 3 \\
\text { - Nanoparticles of } \mathrm{ZnO} \\
\text { - Nanopartic les of fumed silica } \\
\text { - Nanopartic les of } \mathrm{ZrO} 2\end{array}$ \\
\hline $\begin{array}{l}\text { Fin ishing } \\
\text { materials } \\
\text { (Coatings) } \\
\end{array}$ & $\begin{array}{l}\text { Many nanoparticles, surfaces treated } \\
\text { with them often exhib it more than one of } \\
\text { these characteristics. Such as: } \\
\text { - Self-clean ing coatings (TiO2 or } \mathrm{ZnO}) \\
\text { - Scratch resistant coatings ( } \mathrm{SiO} 2 \text { or }\end{array}$ \\
\hline
\end{tabular}

Structural

$\underline{\text { Materials) }}$ 


\begin{tabular}{|c|c|}
\hline & $\begin{array}{l}\mathrm{A} 12 \mathrm{O} 3 \text { ) } \\
\text { - Anti-bacterial coatings (adding } \mathrm{TiO} 2 \text {, } \\
\mathrm{ZnO} \text { or } \mathrm{Ag} \text { ) } \\
\text { - UV and IR reflecting or absorbing } \\
\text { coatings ( } \mathrm{TiO} 2 \text { or } \mathrm{ZnO} \text { ) } \\
\text { - Fire retardant coatings ( } \mathrm{SiO} 2)\end{array}$ \\
\hline $\begin{array}{l}\text { Energy } \\
\text { materials } \\
\text { (Insulation } \\
\text { Materials) }\end{array}$ & $\begin{array}{l}\text { - Nanoporous material "The internal } \\
\text { structure consists of nano-bubbles (nano- } \\
\text { holes)" }\end{array}$ \\
\hline $\begin{array}{l}\text { Energy } \\
\text { materials } \\
\text { (Lighting) }\end{array}$ & $\begin{array}{l}\text { - Nanowires of indium phosphide (InP) } \\
\text { Quantum dot LEDs are nanoscale } \\
\text { semiconductor particles (e.g., silicon or } \\
\text { germanium) }\end{array}$ \\
\hline $\begin{array}{l}\text { Energy } \\
\text { materials } \\
\underline{\text { (Solar }} \\
\text { Energy) }\end{array}$ & $\begin{array}{l}\text { - Silicon nanocrystalline } \\
\text { - Quantum dot }\end{array}$ \\
\hline
\end{tabular}

\section{CONCLUSION}

We can summarize Function introduced to Construction Materials as:

\begin{tabular}{|c|c|}
\hline$\frac{\text { Construction }}{\text { Materials }}$ & Functionality introduced \\
\hline $\begin{array}{c}\begin{array}{c}\text { Structural } \\
\text { materials } \\
\text { (Cement and }\end{array} \\
\underline{\text { Concrete })}\end{array}$ & $\begin{array}{l}\text { - Reduced CO2 emissions. } \\
\text { - Fast compacting rate. } \\
\text { - Improved mechanical performance } \\
\text { (Durability - Strength). } \\
\text { - Enhanced thermal insulation. } \\
\text { - Ease of maintenance (Service life). } \\
\text { - Fire resistant (Fire Protection and } \\
\text { Detection). }\end{array}$ \\
\hline $\begin{array}{c}\text { Structural } \\
\text { materials } \\
\text { (Steel) }\end{array}$ & $\begin{array}{l}\text { - Improving corrosion resistance, } \\
\text { strength formability, and stiffness of } \\
\text { steel. Decrease of wear of stainless } \\
\text { steel. } \\
\text { - Protection against delayed fracturing } \\
\text { of joints and bolts in metals structures. }\end{array}$ \\
\hline $\begin{array}{c}\text { Structural } \\
\text { materials } \\
\underline{(\text { Wood })}\end{array}$ & $\begin{array}{l}\text { - Improve the structural performance } \\
\text { and serviceability of wood. } \\
\text { - Reduce or eliminate the formation of } \\
\text { the random defects that limit the } \\
\text { performance of wood today. } \\
\text { - Improve stiffness and other } \\
\text { mechanical properties. } \\
\text { - Produce a less-toxic alternative to } \\
\text { traditional treated lumber as a construction } \\
\text { material. }\end{array}$ \\
\hline $\begin{array}{l}\text { Structural } \\
\text { materials } \\
(\text { New } \\
\text { Structural } \\
\text { Materials })\end{array}$ & $\begin{array}{l}\text { - Improve strengthen of structural } \\
\text { materials. } \\
\text { - Found new structural materials which } \\
\text { are serving as both skin and building } \\
\text { structure. }\end{array}$ \\
\hline $\begin{array}{c}\text { Fin ishing } \\
\text { materials } \\
\underline{\text { Glass) }}\end{array}$ & $\begin{array}{l}\text { - Increase Energy efficiency. } \\
\text { - Ease of maintenance. } \\
\text { - Clear visibility. } \\
\text { - Sound insulation. } \\
\text { - Fire protection. }\end{array}$ \\
\hline
\end{tabular}

Fin ishing materials

$\underline{\text { (Plastics and }}$ Polymers)

Fin ishing materials $\underline{\text { (Drywall) }}$

Fin ishing materials (Adhesives)

Fin ishing materials (Ceramic $\underline{\text { tiles) }}$

\begin{tabular}{|c|c|}
\hline $\begin{array}{l}\text { Fin ishing } \\
\text { materials } \\
\underline{\text { (Paint) }}\end{array}$ & $\begin{array}{l}\text { - Anti-settling during storage. } \\
\text { - Flame retardancy. } \\
\text { - Ease of maintenance. } \\
\text { - Short dry ing time. } \\
\text { - Scratch resistant. } \\
\text { - Barrier properties. } \\
\text { - Resistance to thermal changes. } \\
\text { - UV resistance. } \\
\text { - Increased reflectivity. } \\
\text { - Long service life with enhanced } \\
\text { performances. }\end{array}$ \\
\hline $\begin{array}{l}\text { Fin ishing } \\
\text { materials } \\
\text { (Coatings) }\end{array}$ & $\begin{array}{l}\text { - Self-cleaning. } \\
\text { - Depolluting. } \\
\text { - Scratch-resistant. } \\
\text { - Anti-icing and anti-fogging. } \\
\text { - Antimicrobial. } \\
\text { - UV protection. } \\
\text { - Corrosion-resistant. } \\
\text { - Waterproofing. }\end{array}$ \\
\hline 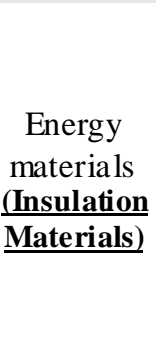 & $\begin{array}{l}\text { - Improve Performance (very low } \\
\text { conductivity values - high R-value). } \\
\text { - Hydrophobic (not retain water in the } \\
\text { structure so that it does not retain } \\
\text { moisture). } \\
\text { - Long service life. } \\
\text { - Easy and economically feasible } \\
\text { installation. } \\
\text { - Impact resistant. }\end{array}$ \\
\hline
\end{tabular}

Energy - Reduce the energy consumed in materials Lighting.

(Lighting)

Energy - Reduce the cost of silicon.

materials - Increase Flexibility of thin films.

(Solar - Improved energy storage.

- Making Plastics and polymers extremely lightweight, corrosion-proof and cheaper to produce than metal.

Increase electrical conductivity, thermal conductivity, improving its capacity to dissipate heat.

- The manufacture of lighter yet stronger drywall.

- Improvement of various properties, including modulus of rupture and modulus of elasticity.

- Material with adhesive surfaces, replacing traditional chemical adhesives. Eliminates residues and increases adhesive force.

- Ease of maintenance.

- Hygiene.

- Resistance to harsh environments.

- Safety.

Ease of maintenance.

Energy)

\section{REFERENCES}


[1] Nanoforum.org (European Nanotechnology Gateway), "Nanoforum Report: Nanotechnology and Construction", November 2006.

[2] George Elvin, "Nanotechnology for Green Building, Green Technology Forum", 2007.

[3] Yankı Keleş, "Observatory Nano (Economical Assessment / Construction sector)", Final report, Bax \& Willems Consulting Venturing, June 2009.

[4] Bjørn Petter Jelleab and Arild Gustavsenc, "Advanced Thermal Building Insulation (From Vacuum Insulation Panels to Nano Insulation Materials)", SFFE Lunch Lecture, Trondheim, Norway, 9th of September, 2010.

[5] Yimin Lin, Jian Lu, Liping Wang, Tao Xu, Qunji Xue, "Surface Nano crystallization by surface mechanical attrition treatment and its effect on structure and properties of plasma nitrided AISI 321 stainless steel", Acta Materialia, 2006.

[6] Michigan Technological University Faculty/Staff Newsletter, "Treating It Right: Using Nanotechnology to Preserve Wood", May 10, 2006.

[7] Wegner, Ted, "Nanotechnology for the Forest Products Industry", US Forest Service Forest Products Laboratory, Madison, WI, January 27, 2007.
[8] McGregor, Steve, "U. T. Dallas-Led Research Team Produces Strong, Transparent Carbon Nanotube Sheets, UT Dallas News Release", Aug. 18, 2005.

[9] Yu, Min-Feng et.al., "Strength and Breaking Mechanism of Multiwalled Carbon Nanotubes Under Tensile Load", Science 287, pp. 637-640, 2000.

[10] Eu ropean Parliament Scientific Technology Options Assessment Committee, "The Role of Nanotechnology in Chemical Substitution", 2007.

[11] Daniel L. Schodek, "Nanomaterials: nanotechnologies and Design", 2009.

[12] Universal Display Corporation, "Creating Innovative Display Technology", 2007.

[13] Hasan, Russell, "The Solar Silicon Shortage and Its Impact on Solar Power Stocks", SolarHo me .org, 2007.

[14] Cientifica, "Nanotechnologies and Energy Whitepaper", February 2007.

[15] Talbot, David, "TR10: Nanocharging Solar", Technology Review, March 12, 2007.

[16] Cientifica, "Nanotechnologies and Energy Whitepaper", February 2007.

[17] Walsh, Ben, "Environmentally Beneficial Nanotechnologies", Oakdene Hollins for Department for Environment, Food and Rural Affairs, May 2007 